\title{
Psychological Well-being of the Older Persons - a descriptive Study
}

\author{
R.Maheswari $^{1}$ and K.Maheswari ${ }^{2}$ \\ ${ }^{1}$ Research Scholar,Department of Social Work, Government Arts and Science College, \\ Perambalur, Tamilnadu, India. \\ ${ }^{2}$ Head, Department of Social Work, Government Arts and Science College, Perambalur, \\ Tamilnadu, India.
}

\begin{abstract}
Well-being is a state of feeling healthy and happy and it includes various domains such as physical, social, psychological, economic, spiritual etc. Psychological well-being (PWB) is the combination of feeling good and functioning effectively and it is an ultimate requirement for all age groups. Psychological well-being does not require individuals to feel good all the time but will also help a person to face painful emotions like disappointment, failure, grief etc and it is a normal part of life. When a person is able to manage these negative or painful emotions, he will be in a position to face the life positively in all aspects. PWB incorporates not only the positive emotions of happiness and contentment, but also such emotions as interest, engagement, confidence, and affection ( Huppert, 2009). Psychological wellbeing at old age not only improves the health but also makes a person to have some control over his life, sense of purpose and experience positive relationships. Thus, the researcher has planned to study the psychological well- being of the older persons residing in rural and urban areas of Perambalur district. Descriptive design was used and 100 respondents were selected using simple random sampling method for this study. A standardized tool on PSW developed by Caron Ryff was used and the major findings of the study revealed that more than half of the respondents $(51 \%)$ had high autonomy, moderate level of environmental mastery, purpose in life and positive relation, and nearly majority of them (59\%) had moderate level of psychological well-being.

Key words: psychological well-being, old age, happiness, autonomy.
\end{abstract}

\section{Introduction}

Old age is an important period in the development stage of a human being and the older persons become more vulnerable and are prone to develop physical and psychological ailments. Age is just a number if a senior citizen sees the life positively and it will lead to successful ageing. Generally, people assume that people at old age suffer from diseases, mental illness, accident prone etc but there is no evidence that a healthy person's intellectual ability decreases with age and they cannot lead an active life as age increases. But when the older persons are inquired about their old age and their health conditions, they have a strong belief that they are not aged and they are physically and psychologically healthy. The gap between reality and the ideal life of older person is really larger and lot of difference is seen in the ageing process of the aged. The contribution of older persons to their families and communities cannot be quantified. It is also evident that older persons are motivated to maintain their economic conditions, health status, and activity levels, adjust to geographical locations, life style, food habits and spiritual life etc. As age increases the physical, psychological loss and psychological growth of older people changes and it forms the important criteria to evaluate the quality of life of the elderly. Well-being can be considered a unifying concept and a characteristic of both the objective and subjective factors which constitute health and quality of life. (sarvimaki, 2006). Well-being is understood as a state of health, happiness and/or prosperity.

\section{Psychological well-being}

Psychosocial wellbeing for older adults could be simply defined as they are living well emotionally and socially in old age. However, living well means different things to different people and each individual's experience of old age will be unique. It is realistic to acknowledge that change or loss might occur in old age, but it is still possible to live 
well despite this. The satisfaction possessed by an individual depends on how much they adjust to and cope with the changes and losses that occur. There are several dimensions of psychosocial wellbeing which includes self reliance, personal growth, purpose, harmonious relationship.

Psychological well-being is a dynamic concept that includes subjective social and psychological dimensions as well as health related behaviour. Contemporary discourse often initially refers to the World Health Organization (WHO 1946) definition, that health is not the mere absence of diseases but a state of well-being. While this definition links the concepts of health and wellbeing, it also has a tendency to underplay the significance and complexity of well-being as a concept. Health tended to be located within biomedical and positivist discourses. Long terms judgments of well-being are likely to be grounded in the continued experience of well-being; The processes of level are likely to affect long-term well-being as well.(Shelly et al.,2004). The Government office for Science Foresight Report on Mental Capital and Well-being (2008) suggests that wellbeing is a dynamic state that is enhanced when people can fulfill their personal and social goals achieve a sense of purpose in society. Rather than being static, well-being emerges from how people interact with the world around them at different points in their lives. It is not necessarily the same as being happy, since anxiety, depression and anger are sometimes to be expected in life.

\section{Review of literature}

Soo et al (2016) have conducted a study on psychological well-being and physical activity in older adults, In Chapman University, findings showed associations between psychological wellbeing and physical activity in adults ages 50 and older. The study included 9,986 English adults over the age of 50 who were assessed up to six times across an average of 11 years. The average age of participants was 63.7 years, with 55 percent of participants being women, and 97 percent of the sample identifying as White.Major findings of the study revealed that higher levels of psychological well-being may precede increased physical activity; therefore, it is possible that psychological wellbeing could be a novel way of not only enhancing psychological health but also increasing physical activity -- which in turn could improve the physical health of a large segment of people in an aging society."

Nagaraj (2017) have identified anxiety and psychological wellbeing of adult and old age people. Data as collected among 120 respondents, 60 were adult (Male and Female) and 60 were old age (Male and Female). For old age, the data was collected from the old age homes and for adult from office sectors. Simple random sampling method was used to collect the sample. The Researcher used for psychological well-being, questionnaire (Sudha Bhogle, 1995) and for anxiety, DASS-21(Depression Anxiety Stress Scale, Lovibond \& Lovibond, 1995) was used. Major findings of the study revealed that there was a significant difference in anxiety and psychological wellbeing among adult and old age and there is a negative correlation between anxiety and psychological wellbeing, that means higher the anxiety lower the psychological wellbeing and lower the anxiety higher the psychological wellbeing

Cachioni et al (2017) have conducted a study on subjective and psychological well-being among elderly participants of a University of the Third Age, A cross sectional study using the following instruments was carried out: a socio-demographic questionnaire (age, gender, education, length of participation in University of the Third Age (U3A) and Life Satisfaction Scale, Positive/Negative Affect Scale; and a Personal Development Scale were used. Major findings of the study revealed that age and gender were the main factors that were significantly associated with overall life satisfaction. Higher education was associated with psychological adjustment. The researcher suggested that participating in a U3A contributes to high levels of subjective and psychological wellbeing.

Connelley et al (2017) have examined psychological well-being among cognitive super agers from their cognitively average-for-age, sameage peers. Thirty-one super agers and 19 cognitively average-for-age peers completed the Ryff 42-item Psychological Well-Being questionnaire, Comprised of 6 subscales. Major findings of the study revealed that the groups did not differ on demographic factors, including estimated pre-morbid intelligence. Consistent with inclusion criteria, super agers had better episodic memory scores. Compared to cognitively averagefor-age peers, super agers endorsed greater levels of Positive Relations with Others. The researcher suggested that while super agers and their cognitively average-for-age peers reported similarly high levels of psychological well-being across multiple dimensions, super agers endorsed greater levels of positive social relationships. 


\section{Aim}

The aim of the study is to assess the psychological well-being among the older persons residing in Perambalur district.

\section{Objectives of the study}

1.) To understand the background characteristics of the respondents.

2.) To find out the psychological well-being among the respondents.

3.) To analyze the association between the selected socio demographic variables and dimensions of psychological well-being.

\section{Methodology}

In this study, the researcher has taken effort to investigate the psychological well-being and has described the characteristics of the respondents along with six dimensions of PWB such as autonomy, environmental mastery, personal growth, positive relationship with others, purpose in life and self-acceptance. The Universe of the study comprised of all the older persons residing in rural and urban areas of Perambalur District, Tamilnadu. The researcher has selected 100 respondents (50 rural and 50 urban) using simple random sampling method from the voters list and the sample size is 100 . The researcher has used self prepared interview schedule to collect the socio demographic information's and a standardized tool on psychological well-being developed by Ryff (1989) was used to measure the psychological wellbeing and it has six dimensions such as autonomy, environmental mastery, personal growth, positive relationship with others, purpose in life and selfacceptance. The scale consists of 42 items. Using Statistical Package for Social Sciences (SPSS) analysis was done and various tests were applied to find the association and difference between variables.

\section{Results and Discussions}

Socio-demographic data: The major findings of the study is explained in detail and the age distribution of the respondents was found that less than half of the respondents $(46 \%)$ were in the group of 60 to 69 years whereas 35 per cent fall under 70 to 79 years of age and only 19.9 per cent of the respondents were above 80 years of age. Majority of the respondents (76\%) were female and 24 per cent male. Regarding marital status of the respondents, 37 per cent are married and living with spouse and more than half of the respondents
$(57 \%)$ are in widowhood, 4 per cent of them are living alone and 2 per cent of the respondents were unmarried. Educational qualification of the older persons revealed that 20 per cent of the respondents are educated up to primary level, 11 per cent have studied middle school, only 3 per cent of them attended up to secondary class and majority of the respondents $(66 \%)$ are illiterate. Majority of the respondents $(77 \%)$ are Hindus whereas 18 per cent of them are Christians and rest follow Islamic religion.

Living arrangements: Living arrangement is an important aspect in understanding the support system given to older persons and it explains the well- being of the older persons. While understanding the living arrangements of the respondents 46 per cent of them are living with children and spouse whereas 47 per cent of them are residing with children and grandchildren and only 4 per cent of them are alone and 3 per cent are living with others. Equal number of the respondents $(50 \%)$ hail from rural and urban areas of perambalur district.

Economic Conditions: While considering the economic status of the respondents, nearly half of the respondents (49\%) earn below Rs.2000 and 48 per cent of the respondents monthly income is between Rs.2001 to Rs.12,000 and few respondents(3\%) monthly income is above Rs.12,000 per month. Regarding the present occupational status, 21 per cent of the respondents are pensioner's whereas 34 per cent of them are doing agriculture and homemakers, and 29 per cent of the respondents work as maids, daily wage earners, petty shop run and business. Ownership of property decides a person's social status as well as decision making power. When it comes to assets of the respondents, few members $(6 \%)$ possess movable property, whereas little more than half of the respondents $(53 \%)$ possess immovable property and 39 per cent of the respondents do not have any property.

Health status: Health is an important indicator of well-being and also it predicts the attitude of the elderly towards ageing process. The presence of diseases and functional disability is unavoidable during old age and it is also clear from the study that, 11 per cent of the respondents health status found to be worse and the respondents one or more acute or chronic diseases, whereas 29 per cent of the respondents current health status was poor, and 42 per cent of them had better health condition and 18 per cent of them have said that they were healthy. 


\section{Findings Related to various test on Psychological Well-Being}

From the study, it is clear that little more than half of the respondents $(51 \%)$ have high level of autonomy whereas 29 per cent have moderate level and 20 per cent have said that they have low of autonomy and this condition is seen more among women elder persons. Regarding environmental mastery, 41 per cent of the respondents have environmental mastery and 27 per cent have said that they have environmental mastery at high level and 32 per cent have low level of environmental mastery.

When it comes to personal growth, majority of the respondents $(61 \%)$ have said that they have high level of personal growth whereas 27 per cent of them have moderate level and 12 per cent of the respondents have low level of personal growth. It is evident from the study that, majority of the respondents $(62 \%)$ have moderate level of positive relations and 15 per cent have high and 23 per cent have low level of positive relation.

Regarding purpose in life of the respondents, majority of them $(70 \%)$ have said that they have moderate level of purpose in life and equal number of respondents ( $30 \%$ each) have high as well as low level of purpose in life. From the study it is seen that little more half of the respondents $(51 \%)$ have moderate level of self acceptance and 29 per cent have high level whereas 20 per cent have low level of self acceptance.

Regarding the overall score of psychological wellbeing, majority of the respondents (59\%) have moderate level of psychological well-being whereas 29 per cent have high and 12 per cent have low level of psychological well-being.

From the various tests it was found that there is a significant association between the age of the respondents with regard to overall score of psychological well-being. It is also found that there is a significant difference between the gender of the respondents with regard to various dimensions of psychological well being such as self acceptance. However there is no significant difference between autonomy, environmental mastery, personal growth, positive relation, purpose in life and overall score of psychological well being.

It is evident that there is a significant association between the number of dependents of the respondents and autonomy dimensions. There is significant difference between the assets of the respondents with regard to overall score of psychological wellbeing. It is also found that there is a highly significant association between the family size of the respondents and various dimensions of psychological wellbeing and overall score of psychological wellbeing. However, there is a significant association between the family size of the respondents with regard to various dimensions of psychological well being such as environmental mastery, positive relation. It is clear the study that there is significant difference among ownership of property and positive relation, purpose in life, self acceptance and overall score of respondents and various dimensions of psychological well-being. From the study it is clear that family plays an important role in enhancing the psychological well being of older persons and the economic conditions decides their relationship and social status in the society. It is understood that psychological well-being must be improved and look after along with the physical well being.

\section{Suggestions}

1. The presence or absence of family support affect general well-being in old age. Family support was found to be important factor for the better psychological well-being. Older people feel helpless and hopelessness at the time the family members support them at the time of needs, they feel secure.

2. The society must accept such mutually supportive philosophy of life, destitution in old age and institutionalisation of elders can be avoided.

3 Policies and laws are essential to improve the social and economic condition of the older persons and to assure their basic right to dignified life.

4. Loneliness, depression, feelings of hopelessness can be prevented when older people interact with community and engage in social activities.

5. Improvement in the health care delivery system and trained professionals and carers are necessary to provide quality care to ageing persons.

6. Good nutrition is necessary for good health. Improvement in nutritional status can be brought about by intervention programmes, in which the importance of nutrient intake, physical activity and exercise can be explained.

7. Men or women, when widowed, suffer from loneliness, marginalisation and the lack of life's companion with whom the surviving spouse shared joys and sorrows through sun and shower. As a widow /widower experience 
specific problems. The attention of care giving by family members is generally reduced. But traditional family system must be enough to have healthy Quality of life.

\section{Conclusion}

India is a developing country belonging to the eastern cultures, with seventy five million elderly in a total population of a thousand million. Living a full life and reaching old age, the older person may look for care and comfort from his fellowmen, providing him psychological succour and social security. To the extent he gets them, his older years yield him a sense of happiness and fulfilment. Physical and psychological well being of the older persons requires a holistic approach that involves the individual, family, community, society, nation and the health professions and it must be planned and executed properly to secure our senior citizens.

\section{References}

[1] Amanda Cook Maher ,Stephanie Kielb, Emmaleigh Loyer, Maureen Connelley, Alfred Rademaker, M.-Marsel Mesulam, Sandra Weintraub, Dan McAdams, Regina Logan,Emily Rogalski, Psychological wellbeing in elderly adults with extraordinary episodic memory, (2017).
[2] Julia Boehm, Eric Kim, Laura Kubzansky, Harvard T. H, Psychological well-being and physical activity in older adults, published in the journal Annals of Behavioral Medicine.(2016).

[3] Meire Cachioni1, Lais Lopes Delfino2, Mônica Sanches Yassuda1, Samila Sathler Tavares Batistoni1, Ruth Caldeira de Melo1, Marisa Accioly Rodrigues da Costa Domingues1, Subjective and psychological well-being among elderly participants of a University of the Third Age, (2017).

[4] Nagaraj M, Anxiety and Psychological WellBeing among Adult and Old Age, The International Journal of Indian Psychology, Volume 4, Issue 3, (2017).

[5] Phillips, Judith, Kristine Ajrouch, and Sarah Hillcoat-Nallétamby, Key Concepts in Social Gerontology (SAGE Publications, 2010), 1213.

[6] Publication Manual of the American Psychological Association, 6th edition (American Psychological Association, 2009) ISBN 1433805618

[7] Sarvimaki, A, Well-being as a being well--a Heideggerian look at well-being. International Journal of Qualitative Studies on Health and Well-being, 4-10, (2006). 